\title{
A General Isotherm Model for Activated Carbon Adsorption of Typical Natural Organic Matters
}

\author{
Xiaodan ZHAO \\ School of Environmental Science \& Engineering \\ Donghua University \\ Shanghai, Songjiang, 201620, China \\ College of Environmental \& Chemical Engineering \\ Shanghai University of Electric Power \\ Shanghai, Yangpu, 200090, China \\ e-mail: z_xiaodan@126.com
}

\author{
Donghui CHEN \\ School of Environmental Science \& Engineering \\ Donghua University, \\ Shanghai, Songjiang, 201620, China \\ e-mail: chendh@dhu.edu.cn
}

\author{
Yurong ZHANG \\ College of Environmental \& Chemical Engineering \\ Shanghai University of Electric Power, \\ Shanghai, Yangpu, 200090, China \\ e-mail: 995008696@qq.com
}

\begin{abstract}
The activated carbon adsorption isotherms of organic matters in natural water were type II and III isotherms, which cannot fitted accurately by the Langmuir and Freundlich models. It is investigated on the different kinds of activated carbon adsorption characteristics for humic, lignin and tannic acid and the fit of the modified SR equation. Results show that the modified SR model has a high degree of fit to all types of isotherms (Coefficient of determination >0.95) compared with the two classical models. In order to make the predicted value of the modified SR model having practical significance, the limiting adsorption capacity, which is related to the pore structure of activated carbon and organic molecular size, is introduced. Limiting equilibrium concentrations are calculated by the modified SR equation and the limiting adsorption capacity.
\end{abstract}

Keywords-natural organic matters; adsorption isotherm; the modified SR model

\section{INTRODUCTION}

Natural organic matters (NOM) are a complex mixture of various organic compounds with different molecular weight and physi-chemical characteristics dissolved in surface water, ground water and soil water[1].

Adsorption by activated carbon is a common method for NOM removal from waters. The theoretical foundation of adsorption process design is adsorption isotherm, which is usually described by two classical models, Langmuir and Freundlich models [2,3]. Langmuir-type adsorption is considered to be a monolayer homogeneous process with no interactions among adsorbates ${ }^{4}$. Freundlich-type adsorption is considered to be a multi-layer process with two parameters used to characterize the adsorption process[2]. Investigations indicated that fitting degree of the two classical models depended on adsorbent dosage and equilibrium concentration $C_{\mathrm{e}}{ }^{5}$. Freundlich model showed better fitting degree than
Langmuir under lower $C_{\mathrm{e}}$; under higher $C_{\mathrm{e}}$, a significant deviation was observed for Freundlich model, while Langmuir model usually achieved a good fitting results; the two models were both unsuitable under the conditions with $C_{\mathrm{e}}$ approaching initial concentrations.

In this study, a general model was introduced to fit different types of adsorption isotherms obtained by different activated carbons with humic acid, lignin and tannic acid, three typical NOMs, as adsorbate. The limiting adsorption capacity related to pore structure and organic matter molecular weights was also put forward to make the predicted value of the general model more practical. The results obtained in this study are expected to provide an insight for analysis and design of adsorption process for NOM removal from natural water by activated carbon.

\section{MATERIALS AND METHOD}

Major headings should be typeset in boldface with the first letter of important words capitalized.

\section{A. Sources of NOM}

Preparation of humic acid. NOM in natural waters was adsorbed by resin firstly, and then the resin was immersed in $4 \% \mathrm{NaOH}$ and $15 \% \mathrm{NaCl}$ for 24 hours at $40{ }^{\circ} \mathrm{C}$. Then $\mathrm{pH}$ of the soak solution was adjusted to $1 \sim 2$, and the obtained precipitates was dissolved in $0.1 \mathrm{~mol} / \mathrm{L} \mathrm{NaOH}$ and filtrated. The filtrate was filtered through a hydrogen type cation exchange column and eluted by desalinated water. The elution was humic acid samples from natural waters.

Preparation of lignin. The lignin complex was precipitated by adding $0.1 \% \quad \mathrm{H}_{2} \mathrm{SO}_{4}$ into filtrate of papermaking wastewater to adjust $\mathrm{pH}$ of 6.0 , and then filtered. The harvested precipitate was dissolved in $0.1 \%$ $\mathrm{NaOH}$ and filtered. The filtrate was precipitated by $0.1 \%$ 
$\mathrm{H}_{2} \mathrm{SO}_{4}$, and the harvested precipitate was dried to prepare solid lignin sample.

The tannic acid (analytical grade) was purchased from Chinese Medicine Group Chemical Reagent Co., Ltd.

\section{B. Pretreatment of Activated Carbon}

Characteristics of the five types of activated carbon used in this study are shown in Table I. The activated carbon was

TABLE I. CHARACTERISTICS OF ACTIVATED CARBON USED IN THIS STUDY

\begin{tabular}{|c|c|c|c|c|c|c|c|}
\hline \multirow[b]{2}{*}{ Materials } & \multirow{2}{*}{$\begin{array}{l}\text { Pore } \\
\text { size } \\
(\mathrm{nm})\end{array}$} & \multicolumn{4}{|c|}{ Pore volume $\left(\mathrm{cm}^{3} / \mathrm{g}\right)$} & \multirow{2}{*}{$\begin{array}{l}\text { Iodine adsorption } \\
\text { value }(\mathrm{mg} / \mathrm{g})\end{array}$} & \multirow{2}{*}{$\begin{array}{l}\text { Methylene blue } \\
\text { adsorption value } \\
(\mathrm{mg} / \mathrm{g})\end{array}$} \\
\hline & & Total pore & Macropore & Mesopore & Micropore & & \\
\hline Coconut shell & 2.57 & 0.4304 & 0.0002 & 0.0985 & 0.3321 & 1085 & 208 \\
\hline Apricot shell & 3.69 & 0.5736 & 0.0065 & 0.2451 & 0.3220 & 980 & 183 \\
\hline Chitin & 4.80 & 0.7216 & 0.0000 & 0.5162 & 0.2354 & 950 & 126 \\
\hline Coal & 3.13 & 0.4896 & 0.0221 & 0.2298 & 0.2377 & 1000 & 165 \\
\hline Nut shell & 3.60 & 0.5615 & 0.0082 & 0.3388 & 0.2145 & 896 & 95 \\
\hline
\end{tabular}

\section{Determination of Adsorption Isotherm}

The activated carbon samples with different weights were added into $150 \mathrm{ml}$ solutions with NOM concentrations of $20 \sim 30 \mathrm{mg} / \mathrm{L}$, and then continuously vibrated for $4 \mathrm{~h}$ at $25^{\circ} \mathrm{C}$. Then samples were taken out of solutions under adsorption equilibrium and filtered through $0.45 \mu \mathrm{m}$ membrane. The absorbance at $254 \mathrm{~nm}$ were measured for filtrate and used to calculate the NOM concentrations. (1).

The adsorption capacity $q_{\mathrm{e}}(\mathrm{mg} / \mathrm{g})$ was calculated as in Eq.

$$
q_{\mathrm{e}}=V\left(C_{0}-C_{\mathrm{e}}\right) / m
$$

Where, $C_{0}$ is initial NOM concentration, $\mathrm{mg} / \mathrm{L} ; C_{\mathrm{e}}$ is the residual (equilibrium) NOM concentration, $\mathrm{mg} / \mathrm{L} ; m$ is the weight of activated carbon, $\mathrm{g} ; \quad V$ is the volume of NOM solution, L.

\section{Adsorption Isotherm Models}

The linear expressions of Langmuir and Freundlich models are shown in Eq. (2) and (3).

$$
\frac{C_{\mathrm{e}}}{q_{\mathrm{e}}}=\frac{1}{q_{\mathrm{m}} b}+\frac{C_{\mathrm{e}}}{q_{\mathrm{m}}}
$$

Where, $b$ is Langmuir constant, and $q_{\mathrm{m}}$ is saturated adsorption capacity, $\mathrm{mg} / \mathrm{g}$.

$$
\ln \left(q_{\mathrm{e}}\right)=\ln \left(k_{\mathrm{f}}\right)+1 / n \ln \left(C_{\mathrm{e}}\right)
$$

Where, $k_{\mathrm{f}}$ is Freundlich constant, $\mathrm{L}^{1 / n} \mathrm{mg}^{(1-1 / n)} / \mathrm{g}$, and $1 / n$ is Freundlich index.

SR model (Eq. (4)) was a general isotherm model built by Summers and Roberts to describe the influence of adsorbent dosage on NOM adsorption[6-9]. immersed in $5 \% \mathrm{HCl}$ for $8 \mathrm{~h}$ firstly, then soaked in the solution adjusted to neutral $\mathrm{pH}$, and then dried at $60^{\circ} \mathrm{C}$. The dried activated carbon was ground to 200 mesh and stored in a desiccator.

$$
q_{\mathrm{e}}=K\left(C_{\mathrm{e}} / C_{\mathrm{C}}\right)^{1 / n}
$$

Where, $K$ is SR adsorption parameter, $C_{\mathrm{C}}$ is adsorbent dosage, and $1 / n$ is isotherm index. Of the NOM isotherm models in the literature, the SR equation appears to be most suitable for practical use as it requires the fewest parameters. However, when applied to a fixed-bed adsorber, Eq. (4) is problematic as the $C_{\mathrm{C}}$ approaches zero, which corresponds to $\mathrm{C}_{\mathrm{e}}$ approaching $\mathrm{C}_{0}, q_{\mathrm{e}}$ becomes infinitely large ${ }^{10}$.

In order to avoid the problems in classical SR model, a mass balance equation for adsorption process was built as shown in Eq. (5):

$$
q_{\mathrm{e}}=\left(C_{0}-C_{\mathrm{e}}\right) / C_{\mathrm{C}}
$$

And thus a modified SR model was built by combining Eq. (4) with Eq. (5) ${ }^{[11]}$.

$$
\ln q_{\mathrm{e}}=\frac{1}{n-1} \ln \left(\frac{C_{\mathrm{e}}}{C_{0}-C_{\mathrm{e}}}\right)+\ln K_{\mathrm{n}} \quad\left(q_{\mathrm{e}} \leq q_{\mathrm{lim}}\right)
$$

Where, $q_{\text {lim }}$ is limiting adsorption capacity of adsorbent, $\mathrm{mg} / \mathrm{g}$.

\section{RESULTS AND DISCUSSION}

\section{A. Adsorption isotherm curves for Different Adsorbates}

The relative molecular weight (MW) of different adsorbates are listed in Table II. The MW of humic acid extracted from natural water was higher than $6 \mathrm{kDa}$, indicating that humic acid represented 30 50\% medium molecular and macromolecular NOM. Lignin was mainly macromolecular substances with $\mathrm{MW}$ higher than $50 \mathrm{kDa}$ accounting for $84.5 \%$. The tannic acid with MW of $1.7 \mathrm{kDa}$ represented about 40 60\% small-molecular NOM in natural water. The adsorption isotherm curves of five types of 
activated carbon on the three representative NOMs are illustrated in Fig. 1.

\begin{tabular}{cccccccc}
\multicolumn{7}{c}{ TABLE II. RELATIVE MOLECULAR WEIGHT OF THREE REPRESENT ATIVE } \\
NOMS \\
$\begin{array}{cccccccc}\text { MW } \\
\text { (kDa) }\end{array}$ & $>50$ & $20 \sim 50$ & $10 \sim 20$ & $6 \sim 10$ & $4 \sim 6$ & $2 \sim 4$ & $<2$ \\
\hline $\begin{array}{c}\text { Humic } \\
\text { acid }\end{array}$ & 40.38 & 46.15 & 9.62 & 3.85 & 0 & 0 & 0 \\
$\begin{array}{c}\text { Lignin } \\
\text { Tannic } \\
\text { acid }\end{array}$ & 84.5 & 9.71 & 1.86 & 0.41 & 1.24 & 0.83 & 1.45 \\
& 7 & Relative MW of $1.701 \mathrm{kDa}$ & &
\end{tabular}
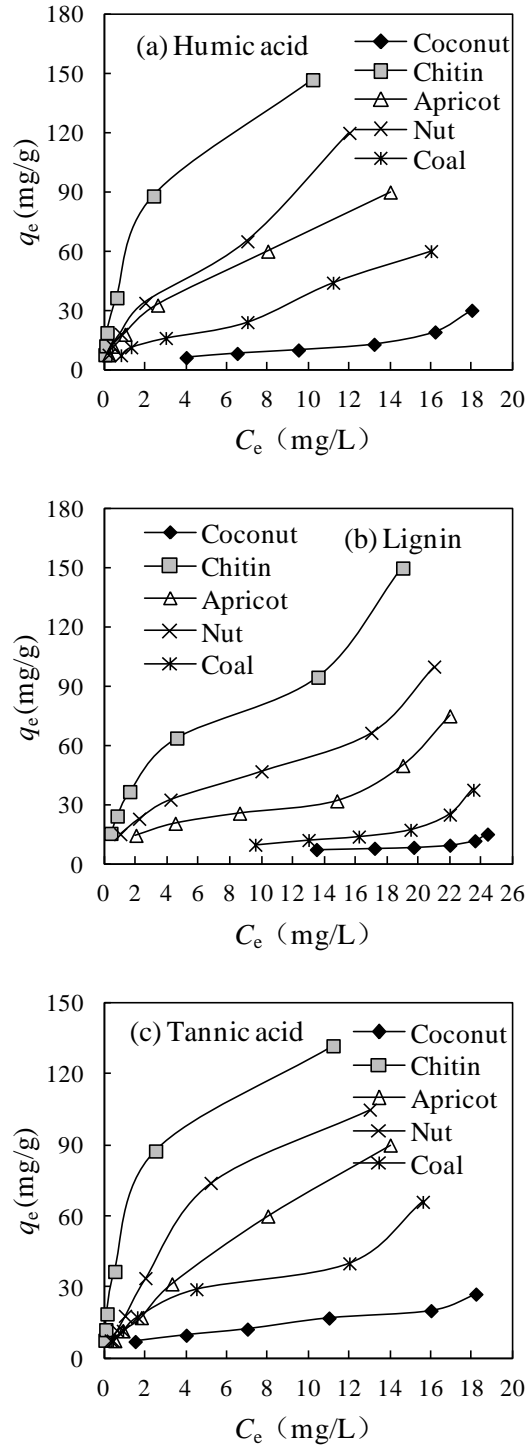

Figure 1. Adsorption isotherm data of 5 kinds of activated carbon on different adsorbents.

The coconut shell activated carbon had the highest iodine adsorption value and methylene blue adsorption value, but illustrated the lowest adsorption performances on the three NOMs. This was mainly attributed to that the two adsorption values characterized adsorption performances of micropore
${ }^{11}$, which accounted for $77.2 \%$ in total pores for pore volume in the coconut shell activated carbon, but the three NOMs were difficult to be adsorbed by micropore. Therefore, the adsorption isotherm showed Type III with wore adsorption performance.

The adsorption isotherm curves of the other four types of activated carbon on humic acid and tannic acid all belonged to Type II and between Type II and III. For lignin with higher MW, the activated carbon showed the lowest adsorption efficiency. The adsorption isotherm curves of chitin and nut shell activated carbon on lignin were Type II, while the other three types on lignin were all Type III.

\section{B. Isothermal Data Fitting of Humic Acid}

The fitting results of humic acid adsorption isotherm by Freundlich, Langmuir and the modified SR models are illustrated in Fig. 2 and Table III.
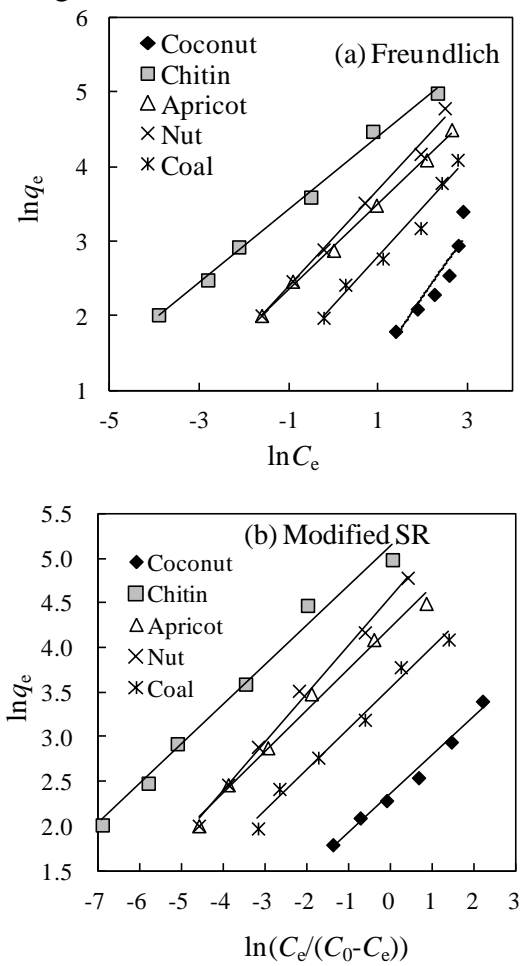

Figure 2. Fitting of humic acid adsorption with different models.

Freundlich model describes the adsorption data more precisely than the Langmuir equaption, but it appears to be not suitble for Type III isotherm as well $\left(\mathrm{R}^{2}<0.92\right)$. That is beacause $q_{\mathrm{e}}$ of Langmuir equaption has limit value and the increasement of $q_{\mathrm{e}}$ with $C_{\mathrm{e}}$ slows down gradually in Freundlich equaption[12,13], which does not coincide with Type III.

The modified SR model predicts that $q_{\mathrm{e}}$ depends on the relative equilibrium concentration $C_{\mathrm{e}} / C_{0}$. The type of adsorption isotherm (Type II or III) exclusively depends on the exponet $1 / n$ defined by the modified SR equaption, the fitting results of which are better than Freundlich and Langmuir $\left(\mathrm{R}^{2}>0.98\right)$. Physically, $K_{\mathrm{n}}$ is the adsorption capacity at $C_{\mathrm{e}}=C_{0} / 2$, which can express the adsorption 
capacity of adsorbent for adsorbate. It is proved by the positive correlations between them in Table III.

TABLE III.THE FITTING PARAMETERS OF THREE KINDS OF MODEL FOR THE ADSORPTION ISOTHERM OF HUMIC ACID BY ACTIVATED CARBON

\begin{tabular}{lllllll}
\hline \multirow{2}{*}{ Activated Carbon } & $\begin{array}{l}\text { Coconut } \\
\text { shell }\end{array}$ & $\begin{array}{l}\text { Apricot } \\
\text { shell }\end{array}$ & Chitin & Coal & $\begin{array}{l}\text { Nut } \\
\text { shell }\end{array}$ \\
\hline \multirow{4}{*}{ Freundlich } & $k_{f}$ & 1.40 & 18.85 & 50.25 & 8.35 & 21.08 \\
& $n$ & 1.06 & 1.74 & 2.04 & 1.50 & 1.53 \\
& $\mathrm{R}^{2}$ & 0.874 & 0.998 & 0.995 & 0.972 & 0.994 \\
\hline \multirow{4}{*}{ Langmuir } & $b$ & 0.03 & 0.80 & 9.00 & 0.21 & 0.61 \\
& $q_{m}$ & 51.02 & 52.08 & 46.30 & 51.02 & 65.79 \\
& $\mathrm{R}^{2}$ & 0.914 & 0.968 & 0.912 & 0.971 & 0.976 \\
\hline \multirow{2}{*}{ Modified } & $K_{n}$ & 10.58 & 68.38 & 170.20 & 34.50 & 97.80 \\
& $n$ & 3.32 & 3.18 & 3.25 & 3.18 & 2.84 \\
& $\mathrm{R}^{2}$ & 0.986 & 0.984 & 0.987 & 0.984 & 0.995 \\
\hline
\end{tabular}

\section{Isothermal Data Fitting of Lignin}

The fitting results of lignin adsorption isotherm by Freundlich, Langmuir and modified SR model are illustrated in Fig. 3 and Table IV.
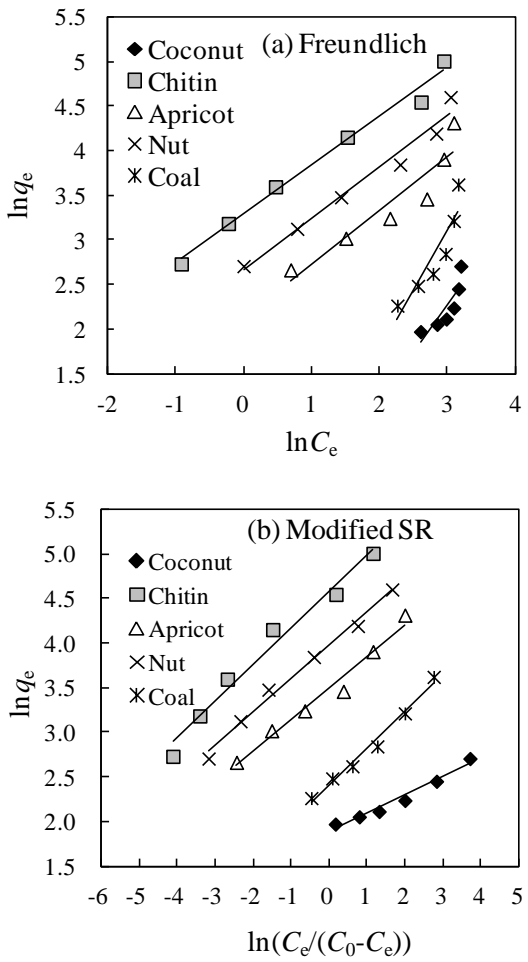

Figure 3. Fitting of lignin adsorption process by different models.

The deviation between predicted value by Freundlich model and experimental data of lignin adsorption isotherm was higher than the Langmuir model for activated carbons except for chitin and nut shell types. This was because macromolecular lignin was difficult to adsorb by activated carbon and the obtained Type III isotherm curve was unsuitable for the fitting by both Freundlich and Langmuir models. The modified SR model showed better fitting results than the two models with $\mathrm{R}^{2}>0.97$, and the obtained parameter $K_{\mathrm{n}}$ was also positively correlated with practical adsorption performance of activated carbon.

TABle IV. The FitTing PARAmeters of ThreE Kinds OF MODEL FOR THE ADSORPTION ISOTHERM OF LIGNIN BY ACTIVATED CARBON

\begin{tabular}{lllllll}
\hline \multirow{2}{*}{ Activated Carbon } & $\begin{array}{l}\text { Coconut } \\
\text { shell }\end{array}$ & $\begin{array}{l}\text { Apricot } \\
\text { shell }\end{array}$ & Chitin & Coal & $\begin{array}{l}\text { Nut } \\
\text { shell }\end{array}$ \\
\hline \multirow{2}{*}{ Freundlich } & $k_{f}$ & 0.42 & 8.40 & 26.74 & 0.40 & 14.42 \\
& $n$ & 0.95 & 1.67 & 1.82 & 0.75 & 1.62 \\
& $\mathrm{R}^{2}$ & 0.724 & 0.868 & 0.987 & 0.836 & 0.972 \\
\hline \multirow{2}{*}{ Langmuir } & $b$ & 0.01 & 0.17 & 0.42 & -0.01 & 0.24 \\
& $q_{m}$ & 96.15 & 53.19 & 104.17 & -113.64 & 74.07 \\
& $\mathrm{R}^{2}$ & 0.740 & 0.875 & 0.983 & 0.893 & 0.958 \\
\hline \multirow{2}{*}{ Sodified } & $K_{n}$ & 6.58 & 33.13 & 97.51 & 11.18 & 53.49 \\
& $n$ & 5.82 & 3.82 & 3.44 & 3.42 & 3.67 \\
& $\mathrm{R}^{2}$ & 0.970 & 0.974 & 0.977 & 0.984 & 0.991 \\
\hline
\end{tabular}

\section{Isothermal Data Fitting of Tannic Acid}

The fitting results of tannic acid adsorption isotherm by the three models are illustrated in Fig. 4 and Table V.
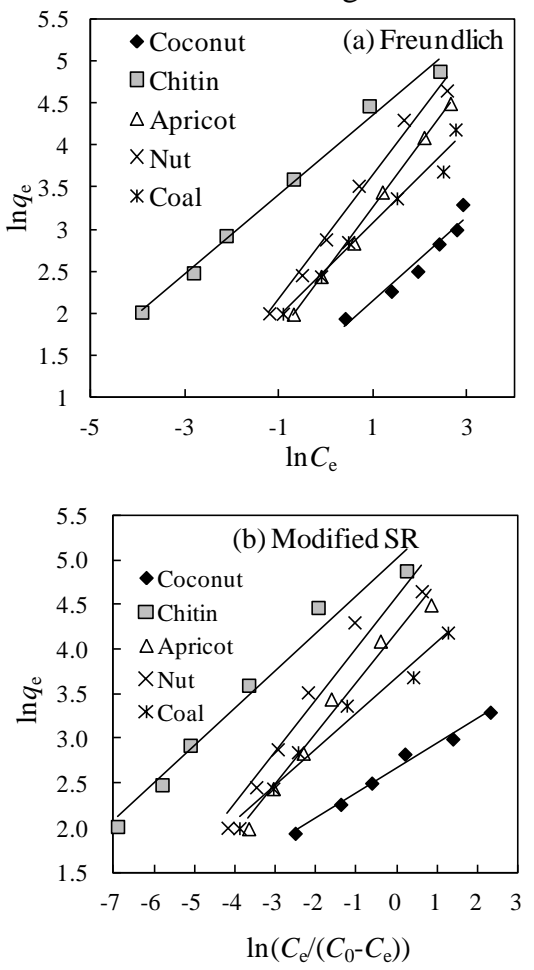

Figure 4. Fitting of tannins adsorption process by different models.

The adsorption isotherm of coconut shell activated carbon on tannic acid was between Type II and Type III, and the fitted $\mathrm{R}^{2}$ value was 0.94 and 0.98 by Freundlich and Langmuir model, respectively, which were both lower than the other activated carbon. The tannic acid with small molecule was easy to adsorb by activated carbon.

At lower $C_{\mathrm{e}}$, the adsorption capacity $q_{\mathrm{e}}$ increased quickly with rising $C_{\mathrm{e}}$ because organic substances can be directly contact with activated sites owing to the lower coverage on the surface of activated carbon. The increase of $q_{\mathrm{e}}$ was slower 
at higher $C_{\mathrm{e}}$ with organic molecules associated in the adsorption pores [11]. Although representing small NOM, the tannic acid was also unable to enter the micropores $(d<$ $0.8 \mathrm{~nm}$ ) with the most activated sites; therefore, the modified SR model also obtained better fitting results.

TABLE V.THE FitTing PARAMETERS OF THREe KindS OF MODEL FOR THE ADSORPTION ISOTHERM OF TANNINS BY ACTIVATED CARBON

\begin{tabular}{lllllll}
\hline \multirow{2}{*}{ Activated Carbon } & $\begin{array}{l}\text { Coconut } \\
\text { shell }\end{array}$ & $\begin{array}{l}\text { Apricot } \\
\text { shell }\end{array}$ & Chitin & Coal & $\begin{array}{l}\text { Nut } \\
\text { shell }\end{array}$ \\
\hline \multirow{2}{*}{ Freundlich } & $k_{f}$ & 5.09 & 12.11 & 48.59 & 12.42 & 18.30 \\
& $n$ & 1.95 & 1.31 & 1.37 & 1.81 & 1.35 \\
& $\mathrm{R}^{2}$ & 0.940 & 0.990 & 0.990 & 0.970 & 0.980 \\
\hline \multirow{2}{*}{ Langmuir } & $b$ & 0.29 & 0.19 & 9.00 & 0.47 & 0.27 \\
& $q_{m}$ & 21.83 & 80.65 & 46.30 & 44.44 & 93.46 \\
& $\mathrm{R}^{2}$ & 0.880 & 0.980 & 0.910 & 0.970 & 0.939 \\
Modified & $K_{n}$ & 14.36 & 65.87 & 151.44 & 39.76 & 97.81 \\
& $n$ & 4.59 & 2.75 & 3.38 & 3.51 & 2.72 \\
& $\mathrm{R}^{2}$ & 0.990 & 0.980 & 0.980 & 0.970 & 0.950 \\
\hline
\end{tabular}

\section{IV.CONCLUSIONS}

(1) Lignin, humic acid and tannic acid represent macromolecular, medium molecular and small molecular NOMs in natural water, respectively. Different types of activated carbon showed different adsorption isotherm curves. The coconut shell activated carbon illustrated Type III adsorption isotherm for the three NOMs with the worst adsorption performances, while the other activated carbon demonstrated Type II isotherm.

(2) The fitting degree of Freundlich model was higher than Langmuir model for adsorption isotherm curves of the five types of activated carbon on the three typical NOMs, but the fitting of Type III isotherm by Freudlich model significantly deviated from the experimental data. The modified SR model showed good fitting performance for both Type II and III isotherms.

\section{ACKNOWLEDGMENTS}

This work was financially supported by Chinese National Natural Foundation Project (51408352).

\section{REFERENCES}

[1] Lamsal R and Walsh M E, Water Research. 45, 10 (2011).

[2] Chung H K, Journal of Industrial \& Engineering Chemistry, 28, (2015).

[3] Edzwald J K. Water quality \& treatment: a handbook on drinking water. (McGraw-Hill, 2011).

[4] Crittenden J C and Trussell R R, MWH's water treatment: principles and design. (John Wiley \& Sons, 2012).

[5] Yu Chen and He Yingying, Technology of Water Treatment, 40, 1, (2014). In Chinese

[6] Koopal L K, Journal of Colloid \& Interface Science, 83, 1, (1981).

[7] Summers R S, Journal of Colloid \& Interface Science, 122, 2, (1988).

[8] Karanfil T, Environmental Science \& Technology, 33, 11, (1999).

[9] Li F and Yuasa A, Water Research, 36, 18, (2002).

[10] Qi S and Schideman L C, Water Research, 42, 13, (2008).

[11] Ding Huanru, Water \& Wastewater Engineering, 37, 9 (2011). In Chinese

[12] Ding L, Environmental Science \& Technology, 40, 1, (2006).

[13] Jarvie M E and Hand D W, Water Research, 39, 11, (2005). 